\title{
Research on the Relationship of Entrepreneurs' Entrepreneurial Passion, Entrepreneurial Leadership and Employee Innovation Behavior
}

\author{
Liu Dong ${ }^{\mathrm{a}, *}$, Zhang Yan ${ }^{\mathrm{b}}$, and Zhou Xiaohu ${ }^{\mathrm{c}}$ \\ School of economics and management, Nanjing University of Science and Technology, Nanjing \\ 210094, China

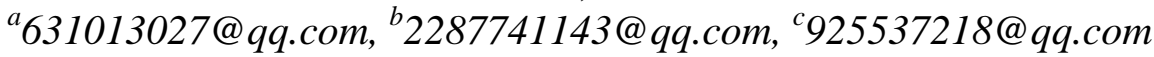

Keywords: Entrepreneurial Passion; Entrepreneurial Leadership; Employee Innovation Behavior; Employee Innovation Efficacy

\begin{abstract}
This study applies a dynamic perspective of interaction between employees and entrepreneurs in start-ups to examine whether the entrepreneurial passion of start-ups will trigger employees' innovative behavior. Based on the emotional infection theory and leadership theory, the research aims to investigate the relationship between entrepreneurs' entrepreneurial passion and employee innovation behavior and its transformation mechanism.
\end{abstract}

This paper constructs a theoretical model including entrepreneurial passion, entrepreneurial leadership and employee innovative behavior. Based the 106 matched samples from Chinese new ventures, the research uses SPSS, Lisrel and other statistical software to carry out statistical test and regression analysis, and the results show that there is a significant positive effect between entrepreneurial passion and employee innovation behavior. Also entrepreneurial passion has a significant positive impact on entrepreneurial leadership and entrepreneurial leadership has samples, the empirical results show that entrepreneurial passion has a significant positive effect on employee innovation behavior. Meanwhile entrepreneurial passion has a significant positive impact on entrepreneurial leadership and entrepreneurial leadership has a significant positive influence on employee innovation behavior. More importantly, entrepreneurial leadership plays a partial mediation role between entrepreneurial passion and employee innovation.

\section{Introduction}

The essence of entrepreneurship lies in innovation. Enterprise innovation is manifested at the organizational, team and individual levels. Employee innovation behavior constitutes the micro-foundation of organizational innovation and internal entrepreneurship, while employee innovation in new ventures is closely linked to entrepreneurs. Many successful start-ups have shown that entrepreneurial passion is critical to the success and development of the enterprise. And many 
entrepreneurial company employees will also show fruitful and innovative behaviors because they are deeply infected by entrepreneurs. However, the transformation mechanism of entrepreneurial passion and employee innovation behavior is still not clear.

In recent years, the influence of emotions on the entrepreneurial process has been paid more and more attention by entrepreneurial research scholars[1]. Most of the existing research on entrepreneurial passion focuses on individual entrepreneurs or companies level. Cardon[2] called for entrepreneurial passion research to break through a single subject, spanning to how entrepreneurs can effectively transfer their entrepreneurial passion to others, which is a new pioneering point in entrepreneurial passion research.

Based on the subjective emotional power of entrepreneurs, with the help of relevant research, this paper explores how the entrepreneurial passion of entrepreneurs landed, studies the impact of entrepreneurial passion on employees as a stakeholder. This article follows the entrepreneurial passion of entrepreneurs - entrepreneurial leadership - employee innovation behavior, not only pays attention to the entrepreneurial passion at the entrepreneur level, but also pays attention to the innovative behaviors that are passed on to employees and motivate them to take advantage of the growth of the enterprise. Transcending the static research of a single subject provides a more dynamic new perspective for the study of entrepreneurial passion. In addition, by introducing the intermediary variable of entrepreneurial leadership, under the background of China's transitional economy, entrepreneurial leadership can help entrepreneurs identify potential information resources and develop entrepreneurial opportunities based on the effective interaction between entrepreneurs and employees. The in-depth exploration of this intermediary mechanism will also help to expand the research on leadership effectiveness in the entrepreneurial environment, thus providing some reference for entrepreneurial entrepreneurs, especially entrepreneurial leadership and innovation incentives within the company, and ultimately promote the realization of innovative behavior.

\section{Theoretical analysis and research hypothesis}

\subsection{Concept definition}

Entrepreneurial Passion. Some scholars combine passion with entrepreneurial activities such as adventure and innovation to create entrepreneurial passion[3]. Baron \& Hannan believes that entrepreneurial passion is the individual's sense of belonging and self-identity to the new business. Cardon[4] defines entrepreneurial passion based on emotional and cognitive perspectives: "Entrepreneurial passion is a strong sense of positive emotion that entrepreneurs experience in activities with entrepreneurial identity and significant entrepreneurial characteristics," and thus promotes the maturity of the concept of entrepreneurial passion. Chen[5] took a motivated approach to investigating how entrepreneurial passion affects venture capitalists' investment decisions. They divide the concept of entrepreneurial passion into emotional and cognitive components ("cognition and behavioral presentations with high personal values" ). Based on the research of many scholars, this study defines entrepreneur's entrepreneurial passion as:entrepreneurs' positive self-positioning for related entrepreneurial activities such as self-investment in opportunity development, creation of new enterprises and development of new enterprises, is the entrepreneur's attitude, belief and subjective evaluation of the enthusiasm of behavior.

Entrepreneurial leadership. The entrepreneurial leadership concept comes from the intersection of entrepreneurship and leadership research[6,7], and is the integration of the concepts of "entrepreneurship”, “entrepreneurial orientation” and "entrepreneurial management” and leadership. It is a new area for integrating entrepreneurial research, leadership research and organizational 
behavior research. Based on previous research, Gupta, MacMillan and Surie[10] combine leadership theory with organizational behavior, and believe that the current challenges to the leaders are outlined and summarized into entrepreneurial leadership. They define entrepreneurial leadership as a leadership behavior that seeks to discover and create strategic value by proactively creating visions, mobilizing subordinates, and earning subordinates' commitments. This definition is used in this study.

Employee innovation behavior. The concept of individual innovation behavior stems from the study of the relationship between creation and innovation. Traditionally, scholars believe that individual creativity is the foundation of organizational innovation. Some scholars regard employee innovation behavior as an individual's unique ability, or a willingness to change positively. Kleysen\&Street[11] summarizes the 289 individual innovations mentioned in 28 papers into five phases: finding opportunities, generating ideas, forming surveys, supporting and applying, and generating innovations that are beneficial to the organization. Taking a look at the definition of employee innovation behavior in the past, the process perspective occupies the mainstream, consistent with most research, this paper believes that employee innovation behavior $\mathrm{i}$ is the starting point of identifying the problem, and is a process of proposing new ideas or new solutions and interacting with organizational colleagues and leaders to seek support.

\subsection{Research hypothesis}

1) The relationship between entrepreneurial passion and employee innovation behavior. Studies have shown that entrepreneurial passion can be transmitted to employees through contagion effects. And when employees get this kind of entrepreneurial passion, this entrepreneurial passion can further promote their innovative behavior. Entrepreneurial-infected employees experience a positive emotion (an important attribute of entrepreneurial passion) that will enable them to adopt an adaptive approach to environmental stimuli and mobilize their energy and attention to address the challenges of facing problems $[5,12]$. When the problem blocks the desire or purpose of rooted in self-identity, individuals who feel entrepreneurial passion are more likely to assign attention and motivation to identify solutions that others have not noticed or have not developed[13], and to use existing knowledge to create new solutions[2]. This reasoning is consistent with Amabile [14], who find that people who are ignited by passion are more likely to pursue innovation.

Therefore, this study believes that the entrepreneurial passion of entrepreneurs will be passed on to employees, which will positively promote their innovative behaviors, and propose the following assumptions:

H1: Entrepreneurial passion has a positive impact on employee innovation behavior.

2) The relationship between entrepreneurial passion and entrepreneurial leadership. The core elements of entrepreneurial leadership are vision setting and task setting, including building challenges, absorbing uncertainty, removing obstacles, building commitments, and clarifying constraints. Baron[12] points out that entrepreneurs with more positive experiences (one aspect of entrepreneurial passion) are more likely to mobilize their energies and concerns to deal with the challenges they face as a result of their wide attention and divergent thinking, and a high level of alertness to new opportunities. Cardon[4] believes that entrepreneurial passion for activities related to specific identities will lead entrepreneurs to set more challenging goals, leading to higher levels of creative solutions and higher levels of absorption. Therefore, the entrepreneurial passion of entrepreneurs helps them to build challenges in their work and to absorb the uncertainties of opportunities in the environment.

Entrepreneurial passion includes positive emotions and identity. Studies have shown that positive emotions help individuals to positively evaluate their own abilities and expected outcomes. People 
with positive emotional states often try to maintain their positive states and are more likely to adhere to current behavioral guidelines. When the current goals are met, they can turn their attention to other goals and continue to adhere to actions that further enhance his positive well-being. As a result, entrepreneurial passion helps entrepreneurs remove barriers and build higher organizational commitments.

In addition, leaders with entrepreneurial passion will have greater risk perception and ability to respond keenly[12]. Cardon[13] points out that entrepreneurial passion is closely linked to specific matching behaviors, such as the role of the inventor's passion associated with the persona's behavior, such as active and systematic scanning of risk ideas, which helps identify market gaps and ways to exploit these gaps. Therefore, entrepreneurial passion helps entrepreneurs clarify constraints and understand the constraints of the current market.

Entrepreneurial passions include the strength and courage, the enormous incentives and the indomitable pursuit of challenging goals that give entrepreneurs the ability to create creativity and identify potential entrepreneurial opportunities. Strong willingness and adventurous spirit are important manifestations of entrepreneurial passion, and the five aspects of entrepreneurial leadership are closely related to entrepreneurial passion. Therefore, this paper puts forward hypothesis 2:

H2: Entrepreneurial passion has a significant positive impact on entrepreneurial leadership.

3) The relationship between entrepreneurial leadership and employee innovation behavior. Since most start-ups are made up of a core (important) entrepreneur and a small group of people, this core entrepreneur is critical to the team and its leadership style can influence organizational innovation [15]. The impact of leadership on employee innovation at the individual level is manifested in three mechanisms: motivation, emotion, and cognition. Leadership can directly influence employee motivation, emotion, and cognitive processes [16].In particular, existing research indicates that leadership influences employee innovation not only by promoting their mental state, but also by supporting the social context of the innovation process such as the identification of problems, the collection of information and the creation, evaluation and modification of ideas.

To be specific: first, the essence of entrepreneurial leadership is to create a vision and guide followers to achieve this vision, helping to integrate a large number of interdependent members for strategic value creation. Second, entrepreneurial leaders tend to tolerate ambiguity, enthusiasm, etc., emphasizing adaptation to uncertain environments, identifying new opportunities and leading to continuous innovation and change [17]. Finally, entrepreneurial leaders are willing to create an innovative atmosphere of adventure, trust and support, and fully empower employees to innovate and use incentives to continually reinforce employees' innovative intrinsic motivation, which helps drive the generation of the employee innovation [18]. Thus, we propose hypothesis 3 :

H3: Entrepreneurial leadership has a significant positive impact on employee innovation behavior.

4) The intermediary role of entrepreneurial leadership. The influence of entrepreneurial passion on employee innovation behavior is based on the interaction between entrepreneurs and employees. The most intuitive and common form of interaction is leadership behavior. Leadership behavior is essentially an emotional process in which leaders demonstrate emotions and attempt to evoke the emotions of organizational members, so entrepreneurial leadership is an important factor in employee innovation behavior. In addition, the five aspects of entrepreneurial leadership behavior are closely related to the positive emotion of entrepreneurial passion and the identity of entrepreneurs. If the entrepreneur's entrepreneurial passion is higher, it will demonstrate a greater support for entrepreneurship, such as innovation and adventure, in accordance with entrepreneurial identity, namely, the implementation of entrepreneurial leadership behavior, which in turn will create an atmosphere that encourages innovation, that is, employee innovation behavior may be more likely to occur. 
Based on the above analysis, the relationship between entrepreneurial passion and employee innovation behavior is still unclear. The entrepreneurial leadership variable reflects the interaction between entrepreneurs and employees, and research on entrepreneurial leadership and employee innovation behavior has matured. Based on the analysis of psychology, this study builds a theoretical model between entrepreneurial passion, entrepreneurial leadership, and employee innovation behavior based on the research of Cardon, Brgust and other scholars. It is believed that entrepreneurial leadership plays an intermediary role in the model as the interaction mechanism between leadership and employees. Thus, we propose hypothesis 4:

H4: Entrepreneurial leadership plays a mediating role in entrepreneurial passion and employee innovation.

In summary, this paper constructs a relational conceptual model as shown in Figure 1.

H1

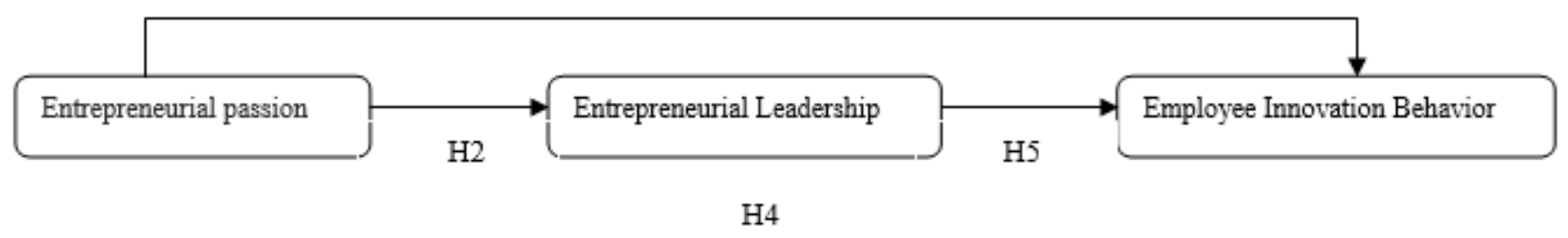

Figure 1: Research framework of this paper

\section{Research design}

\subsection{Samples and data}

1) Definition of research objects. This study initially targeted the respondents to start-ups and start-up teams in the Chinese context. Referring to the selection criteria of the sample in Chen's study of entrepreneurial passion for investors ' strategic decisions, the following two easy-to-understand criteria were selected: (1) start-ups with a time of no more than 10 years, and (2) no initial public offerings.

2) Questionnaire design process and cross matching design. The questionnaire design of this study has gone through three processes: scale translation, discussion and modification, questionnaire self-test and pre-test. The resulting complete scale consists of two parts: the leadership questionnaire (including the control variables of the entrepreneur's individual and the company's basic situation;one main variable: the employee's innovative behavior); the employee questionnaire (including three variables: the entrepreneur's entrepreneurial passion; entrepreneurial leadership; employee innovation effectiveness). One of the paired samples includes a leadership questionnaire and a number of employee questionnaires, and the average of the employee's assessments is paired with the leadership questionnaire to complete the cross-matching.

3) Data collection and sample situation. Data collection. Since the research object is a start-up enterprise, the sample of this study is locked in the Pioneer Park and the Science Park. The questionnaire was issued from June to September 2017 with a time span of 3 months; the distribution area was concentrated in Nanjing and Shanghai. The questionnaire is distributed in two parts, and is marked according to the company's short name to match. A total of 342 questionnaires were distributed in the Pioneer Park and Science Park, effectively matching 71. Considering that the sample is difficult to obtain, it is combined with an online questionnaire collection method. Excluding the incomplete questionnaire and the unqualified questionnaire, the final number of 
matching samples was 106.

Sample description. From the background information of the individuals in the study sample, in the sample, males accounted for $67 \%$ of the company's leadership and $33 \%$ of women. From the perspective of education, the highest level of education led by the subjects is mainly junior college and undergraduate, and the number of undergraduate students is more than half. The entrepreneurial leaders of enterprises are mostly concentrated in the age of $26-45$, accounting for $66.1 \%$. More than half of the entrepreneurs had no entrepreneurial experience before, accounting for $55.7 \%$.

The survey results of corporate background data show that the subjects are mainly concentrated in IT, Internet, high-tech, machinery and equipment and commercial trade, of which IT and Internet account for the largest number, accounting for 36.8\%. There are significant differences in the nature of enterprises, and private enterprises are over $70 \%$. The company's size is mainly concentrated in 4-15 people. The average age of the company's employees is also young. The level of education of employees is similar to that of entrepreneurs, accounting for $45.3 \%$ of undergraduate education.

\subsection{Variable measurement}

1) Explanatory variables. The explanatory variable in this research model is entrepreneurial passion. We use the maturity scale of Cardon [19] and refer to the expression of Brgust et al. [20] to measure the entrepreneur's passion for discovering opportunities, starting a business, and promoting business development. The scale of entrepreneurial passion is measured by employees and uses a five-point Likert scale.

2) Explained variable. Employee innovation behavior is the interpreted variable of this study. This paper adopts the employee innovation behavior scale compiled by Scott \& Bruce [21], which is clear, visual and has high reliability and validity. The scale has a total of six items, including five specific items and one summary item. The specific measurement content is reflected in the generation of employee's innovative ideas, seeking support, and the actual operation of the innovation plan. The scale of employee innovation behavior is measured by entrepreneurs.

3) Mediation variable. According to the model, entrepreneurial leadership is the mediator variable of this paper. Refer to the more mature scale of Gupta et al [10] and refer to the translation of Xu Juan [22]. The scale contains 26 items, mainly reflecting leadership behavior, and entrepreneurial leadership is measured by employees.

Control variables. The control variables in this paper mainly include four types: basic personal information of entrepreneurs, basic information of the company, employees (team level), and employee innovation efficacy. Among them, this article has obtained a specific adaptation scale of innovative self-efficacy by consulting with domestic scholar Professor Gu Yuandong. The scale includes eight items that are evaluated by employees.

4) Sample pretest. In the pre-test phase of the sample, the author conducted a field distribution of the leadership questionnaire and the employee questionnaire. Finally, 23 leadership questionnaires and 48 employee questionnaires were obtained, and the reliability and factor analysis were performed for the variables of the two original questionnaires. The reliability analysis test shows that the overall alpha coefficient of the leadership questionnaire (the questionnaire filled out by the entrepreneur) is 0.829, while the overall alpha coefficient of the employee questionnaire (the questionnaire filled out by the employee) is 0.885 , indicating that the pre-tested dosage form has a high Internal consistency can be used for research.

To test the structural validity of the pre-test questionnaire, we performed an exploratory factor analysis. Principal component extraction is performed for the leadership questionnaire and the employee questionnaire. The extraction method is based on the eigenvalue greater than 1 , and is rotated according to the maximum variance method. The resulting load map shows that the factor 
load of each item is greater than 0.6, and the cumulative interpretation variance of the main component analysis is above $80 \%$. The formal questionnaire (Questionnaire II) of this paper was finally formed under the combination of the relevant participants' suggestions for the questionnaire.

5) Scale reliability. The problem of homologous variance. This article avoids this problem to some extent by two methods. First of all, the use of cross-matching design of entrepreneurs and employees to ensure that the data is objective and fair, while avoiding the problem of a single source of data. Secondly, for the employee questionnaire, this study sets a reverse question on the item to avoid the influence of the assessor's equilibrium convergence deviation and negative deviation on the test results [23].

Scale reliability analysis. The sample data is analyzed by Spass software. The $\alpha$ coefficient of the whole scale is 0.962 . It can be seen that the Cronbach's $\alpha$ coefficient of each scale is basically above 0.7 , which indicates that the scale selected in this paper has high internal consistency, stability and reliability ,with a high degree of credibility.

Scale validity analysis. Based on the pre-test, this paper uses Lisrel to perform confirmatory factor analysis on 106 data obtained. The results of the confirmatory factor analysis in this paper are shown in Table 1, which shows: $\chi^{2} / \mathrm{df}=1.49 \leqslant 3$. It shows that the fitting effect is very satisfactory; CFI, IFI, NNFI is greater than 0.95, indicating that the fit is quite ideal; the fitting condition is better when RMSEA $\leqslant 0.08$. Overall, the scale has good structural validity.

Table 1 Confirmatory factor analysis results of the structural validity of the scale

\begin{tabular}{ccccccc}
\hline$\chi^{2}$ & df & $\chi^{2} / \mathrm{df}$ & CFI & IFI & NNFI & RMSEA \\
\hline 2274.03 & 1529 & 1.49 & 0.95 & 0.95 & 0.95 & 0.065 \\
\hline
\end{tabular}

\section{Hypothesis testing and discussion}

\subsection{Normality, Multicollinearity, Sequence correlation}

In this paper, SPSS is used for normality test, and combined with the graphical method (with Q-Q map) and the statistical index method (using Kolmogorov-Smirnov). In the normal Q-Q of each variable, the scatter point corresponding to the sample data basically falls near the $45^{\circ}$ line starting from the origin, indicating that the data is approximately normal distribution. In the K-S test, the P values (progressive significance) were all greater than 0.05 , so the data showed an approximately normal distribution.

This study used the VIF method to diagnose the existence of multiple collinearity problems. The VIF values obtained by each regression model are below the critical value of 10 , which means that the collinearity problem is not significant.

The problem related to the sample sequence of this study also does not exist. First of all, the sample books in this study are all cross-sectional data, there is no sample value in different periods; secondly, the diagnostic results show that the DW values of all models are distributed around 2.0.

\subsection{Correlation analysis}

As shown in Table 2, there is a significant positive correlation between entrepreneurial passion and employee innovation behavior $(\mathrm{p}=0.528$, Sig=0.01), which is in line with our main effect prediction, hypothesis 1 . The correlation coefficient between entrepreneurial passion and 
entrepreneurial leadership is positively correlated with the 0.01 level. Entrepreneurial leadership is also significantly positively correlated with employee innovation behavior, which is in line with hypotheses 2 and 3. In addition, from the Pearson correlation coefficient between the relevant control variables and the research variables, it can be seen that the employee's innovation efficacy has a significant positive correlation with the result variable employee innovation behavior. It shows that this control variable has certain influence on the research variables, and there is no high correlation problem in each variable, which has certain differential validity.

Table 2 Pearson Correlation Coefficients Between Variables

\begin{tabular}{|c|c|c|c|c|c|c|c|c|c|c|c|c|c|c|c|c|}
\hline & 1 & 2 & 3 & 4 & 5 & 6 & 7 & 8 & 9 & 10 & 11 & 12 & 13 & 14 & 15 & 16 \\
\hline 1 & 1 & & & & & & & & & & & & & & & \\
\hline 2 & $.232 *$ & 1 & & & & & & & & & & & & & & \\
\hline 3 & $-.270 * *$ & $-.537 * *$ & 1 & & & & & & & & & & & & & \\
\hline 4 & -0.037 & 0.094 & -0.082 & 1 & & & & & & & & & & & & \\
\hline 5 & $.304 * *$ & $.344^{* *}$ & $-.232 *$ & 0.086 & 1 & & & & & & & & & & & \\
\hline 6 & $-.232 *$ & $-.311^{* *}$ & 0.186 & -0.048 & $-.748 * *$ & 1 & & & & & & & & & & \\
\hline 7 & 0.099 & 0.164 & $-.264 * *$ & -0.083 & 0.076 & -0.063 & 1 & & & & & & & & & \\
\hline 8 & -0.156 & $-.196 *$ & 0.170 & -0.036 & $-.208^{*}$ & $.204 *$ & -0.117 & 1 & & & & & & & & \\
\hline 9 & 0.178 & -0.106 & 0.130 & 0.135 & $.217^{*}$ & -0.179 & 0.096 & $-.245^{*}$ & 1 & & & & & & & \\
\hline 10 & 0.066 & $-.192 *$ & $.263^{* *}$ & -0.086 & 0.050 & 0.182 & -0.061 & 0.010 & $.222 *$ & 1 & & & & & & \\
\hline 11 & -0.005 & 0.129 & -0.160 & $.403^{* *}$ & -0.049 & 0.143 & -0.127 & -0.14 & -0.044 & -0.164 & 1 & & & & & \\
\hline 12 & -0.005 & 0.005 & 0.066 & -0.068 & -0.122 & 0.118 & $-.302^{* *}$ & 0.107 & -0.043 & -0.006 & 0.07 & 1 & & & & \\
\hline 13 & -0.037 & -0.172 & 0.059 & 0.067 & -0.103 & 0.071 & $-.210^{*}$ & 0.170 & -0.058 & -0.145 & 0.065 & $.511^{* *}$ & 1 & & & \\
\hline 14 & 0.127 & 0.006 & -0.088 & -0.066 & -0.041 & 0.157 & -0.108 & 0.108 & 0.123 & 0.052 & 0.054 & $.463^{* *}$ & $.542 * *$ & 1 & & \\
\hline 15 & 0.020 & -0.027 & 0.062 & 0.051 & -0.028 & -0.038 & -0.180 & -0.058 & 0.093 & $-.257 * *$ & 0.158 & $.269 * *$ & $.270^{* *}$ & 0.170 & 1 & \\
\hline 16 & 0.013 & 0.004 & 0.050 & 0.104 & -0.130 & 0.134 & -0.107 & 0.088 & 0.175 & -0.031 & 0.144 & $.291 * *$ & $.528 * *$ & $.561^{* *}$ & $.319^{* *}$ & k 1 \\
\hline
\end{tabular}

Note: 1 gender, 2 marriages, 3 ages, 4 highest education, 5 entrepreneurial experience, 6 number of startups before, 7 company's industry, 8 company nature, 9 company size, 10 employee age, 11 employee qualifications, 12 employee innovation efficacy, 13 entrepreneurial passion, 14 entrepreneurial leadership, 15 environmental dynamics, 16 employee innovation behavior ** Significantly correlated at the 0.01 level (both sides), * significantly correlated at the 0.05 level (two sides)

\subsection{Multiple regression analysis}

This paper mainly uses multiple linear regression models to test the theoretical models and hypotheses constructed in the paper.

1) Entrepreneurial passion and employee innovation behavior. The results of regression analysis are shown in Table 3. As shown in model 2 in the table, entrepreneurial passion has a positive impact on employee innovation behavior $(\beta=0.734$, Adjusted $\mathrm{R} 2=0.305)$, and its regression coefficient reaches a significant level (Sig. $=0.000<0.05, \mathrm{~F}=4.552$ ). Thus, the main effect of entrepreneurial passion and employee innovation behavior is verified, and Hypothesis 1 is supported. At the same time, Model 1 is the analysis of the impact of various control variables on employee innovation behavior. It can be found that the positive impact of company size and employee innovation efficacy on employee innovation behavior is significant, which proves that it is necessary to include it in the control variables. 
Table 3 Regression Analysis of Entrepreneurial Passion and Employees' Innovative Behavior

\begin{tabular}{lcccccc}
\hline & B & $\begin{array}{c}\text { Model 1 } \\
\text { Standard } \\
\text { coefficient }\end{array}$ & Sig & B & $\begin{array}{c}\text { Model 2 } \\
\text { Standard } \\
\text { coefficient }\end{array}$ & Sig \\
\hline (Constant) & 1.696 & & 0.050 & 0.046 & & 0.954 \\
$\begin{array}{l}\text { Highest education } \\
\text { Entrepreneurial }\end{array}$ & 0.023 & 0.026 & 0.838 & -0.050 & 0.007 & 0.617 \\
experience & -0.130 & -0.094 & 0.549 & -0.168 & -0.031 & 0.371 \\
$\begin{array}{l}\text { Number of startups } \\
\text { before }\end{array}$ & 0.049 & 0.090 & 0.567 & 0.046 & 0.068 & 0.537 \\
$\begin{array}{l}\text { Industry } \\
\text { Company nature }\end{array}$ & -0.009 & -0.033 & 0.752 & -0.004 & -0.020 & 0.860 \\
Company size & 0.083 & 0.121 & 0.244 & 0.053 & 0.046 & 0.391 \\
Employee age & 0.134 & 0.275 & 0.013 & 0.142 & 0.160 & 0.002 \\
Staff education & -0.086 & -0.078 & 0.479 & 0.023 & -0.006 & 0.827 \\
Employee innovation & 0.090 & 0.098 & 0.453 & 0.119 & 0.105 & 0.253 \\
efficacy & 0.329 & 0.250 & 0.015 & -0.057 & 0.183 & 0.673 \\
Entrepreneurial passion & & & & 0.734 & 0.548 & 0.000 \\
R2 & & 0.181 & & & 0.391 & \\
Adjusted R2 & & 0.075 & & & 0.305 & \\
F & & 1.713 & & & 0.210 & \\
$\triangle \mathrm{R}^{2}$ & & 0.181 & & & 31.811 & \\
$\triangle \mathrm{F}$ & & 1.713 & & & & \\
\hline
\end{tabular}

Entrepreneurial passion and entrepreneurial leadership. It is easy to know from Table 4 that entrepreneurial passion has a significant positive effect on entrepreneurial leadership behavior ( $\beta=0.399$, Adjusted R2=0.387, Sig. $=0.000<0.05, F=6.105$ ), and the model has a good explanatory power. Accordingly, Hypothesis 2 is verified.

Table 4 Regression Analysis of Entrepreneurial Passion and Entrepreneurial Leadership

\begin{tabular}{lcccccc}
\hline & B & $\begin{array}{c}\text { Model 1 } \\
\text { Standard } \\
\text { coefficient }\end{array}$ & Sig & B & $\begin{array}{c}\text { Model 2 } \\
\text { Standard } \\
\text { coefficient }\end{array}$ & Sig \\
\hline (Constant) & 2.127 & & 0.000 & 1.230 & & 0.013 \\
Industry & -0.005 & -0.030 & 0.759 & -0.003 & -0.015 & 0.859 \\
Company size & 0.068 & 0.216 & 0.032 & 0.073 & 0.230 & 0.011 \\
Staff education & 0.033 & 0.055 & 0.643 & 0.049 & 0.082 & 0.441 \\
Employee Innovation & 0.374 & 0.437 & 0.000 & 0.164 & 0.192 & 0.048 \\
Efficacy & & & & 0.399 & 0.476 & 0.000 \\
Entrepreneurship & & & & & 0.463 & \\
$\mathrm{R}^{2}$ & & 0.316 & & & 0.387 & \\
Adjusted $\mathrm{R}^{2}$ & & 0.227 & & & 6.105 & \\
$\mathrm{~F}$ & & 3.573 & & & 0.148 & \\
$\triangle \mathrm{R}^{2}$ & 0.316 & & & & 25.286 & \\
$\triangle \mathrm{F}$ & & 3.573 & & & & \\
\hline
\end{tabular}

Entrepreneurial leadership and employee innovation behavior. It is easy to know from Table 5 that entrepreneurial leadership behavior has a significant positive effect on employee innovation behavior $(\beta=0.845$, Adjusted R2 $=0.301$, Sig. $=0.000<0.05, F=4.471)$, and the explanatory power of the model 
is also significant. Thus, Hypothesis 3 is supported.

Table 5 Regression analysis of entrepreneurial leadership and employee innovation behavior

\begin{tabular}{|c|c|c|c|c|c|c|}
\hline & \multicolumn{3}{|c|}{ Model 1} & \multicolumn{3}{|c|}{ Model 2} \\
\hline & B & $\begin{array}{l}\text { Standard } \\
\text { coefficient }\end{array}$ & Sig & B & $\begin{array}{l}\text { Standard } \\
\text { coefficient }\end{array}$ & Sig \\
\hline (Constant) & 1.696 & & 0.050 & -0.102 & & 0.900 \\
\hline Industry & -0.009 & -0.033 & 0.752 & -0.005 & -0.017 & 0.853 \\
\hline Company size & 0.134 & 0.275 & 0.013 & 0.076 & 0.157 & 0.108 \\
\hline Staff education & 0.090 & 0.098 & 0.453 & 0.062 & 0.068 & 0.552 \\
\hline $\begin{array}{l}\text { Employee Innovation } \\
\text { Efficacy }\end{array}$ & 0.329 & 0.250 & 0.015 & 0.013 & 0.010 & 0.920 \\
\hline $\begin{array}{l}\text { Entrepreneurial } \\
\text { leadership }\end{array}$ & & & & 0.845 & 0.549 & 0.000 \\
\hline $\mathrm{R}^{2}$ & & 0.181 & & & 0.387 & \\
\hline Adjusted $\mathrm{R}^{2}$ & & 0.075 & & & 0.301 & \\
\hline $\mathrm{F}$ & & 1.713 & & & 4.471 & \\
\hline$\triangle \mathrm{R}^{2}$ & & 0.181 & & & 0.206 & \\
\hline$\triangle \mathrm{F}$ & & 1.713 & & & 30.946 & \\
\hline
\end{tabular}

4) The intermediary role of entrepreneurial leadership. From Table 6, Model 2, the main effect of entrepreneurial passion on employee innovation behavior is significant $(\beta=0.734$, Sig. $=0.000$ ). In Model 3, both entrepreneurial passion and entrepreneurial leadership are included in the independent variables. At this time, it can be seen that the positive effect of entrepreneurial passion on employee innovation behavior is still significant $(\beta=0.506$, Sig. $=0.000)$, and the mediation effect is obvious. That is, entrepreneurial leadership plays a mediating role between entrepreneurial passion and employee innovation behavior, and acts as a partial intermediary.

Table 6 Test of the mediating effect of entrepreneurial leadership between entrepreneurial passion and employee innovation behavior

\begin{tabular}{|c|c|c|c|c|c|c|c|c|c|}
\hline & \multicolumn{3}{|c|}{ Model 1} & \multicolumn{3}{|c|}{ Model 2} & \multicolumn{3}{|c|}{ Model 3} \\
\hline & B & $\begin{array}{l}\text { Standard } \\
\text { coefficient }\end{array}$ & Sig & B & $\begin{array}{l}\text { Standard } \\
\text { coefficient }\end{array}$ & Sig & B & $\begin{array}{c}\text { Standard } \\
\text { coefficient }\end{array}$ & Sig \\
\hline (Constant) & 1.696 & & 0.050 & 0.046 & & 0.954 & -0.657 & & 0.399 \\
\hline Industry & -0.009 & -0.033 & 0.752 & -0.004 & -0.016 & 0.860 & -0.003 & -0.010 & 0.903 \\
\hline Company size & 0.134 & 0.275 & 0.013 & 0.142 & 0.292 & 0.002 & 0.101 & 0.207 & 0.027 \\
\hline Staff education & 0.090 & 0.098 & 0.453 & 0.119 & 0.130 & 0.253 & 0.091 & 0.100 & 0.354 \\
\hline $\begin{array}{l}\text { Employee } \\
\text { Innovation } \\
\text { Efficacy }\end{array}$ & 0.329 & 0.250 & 0.015 & -0.057 & -0.043 & 0.673 & -0.151 & -0.114 & 0.246 \\
\hline $\begin{array}{l}\text { Entrepreneurial } \\
\text { Passion }\end{array}$ & & & & 0.734 & 0.569 & 0.000 & 0.506 & 0.392 & 0.000 \\
\hline $\begin{array}{l}\text { Entrepreneurial } \\
\text { leadership }\end{array}$ & & & & & & & 0.572 & 0.371 & 0.001 \\
\hline $\mathrm{R}^{2}$ & & 0.181 & & & 0.391 & & & 0.465 & \\
\hline Adjusted $\mathrm{R}^{2}$ & & 0.075 & & & 0.305 & & & 0.383 & \\
\hline $\mathrm{F}$ & & 1.713 & & & 4.552 & & & 5.661 & \\
\hline$\Delta R^{2}$ & & 0.181 & & & 0.210 & & & 0.074 & \\
\hline$\triangle \mathrm{F}$ & & 1.713 & & & 31.811 & & & 12.610 & \\
\hline
\end{tabular}

In order to further verify whether the mediating role of entrepreneurial leadership in this study is 
really significant, this paper conducts the mediation effect test according to the mediation effect analysis program proposed by Zhao et al. with reference to the steps of Chen Rui et al. [24]. The sample size was chosen to be 5000, under the $95 \%$ confidence interval. The test results are shown in Table 7. In the fourth model, the results of the mediation effect test (ie, indirect effect) of entrepreneurial leadership did not include 0 (BootLLCI=0.0667, BootULCI=0.4561), indicating that the mediating effect of entrepreneurial leadership is significant, and the effect coefficient is 0.2283. And found that after controlling this intermediary, the effect of entrepreneurial passion on employee innovation behavior is still significant, and the interval (LLCI $=0.2306$ ULCI $=0.7806$ ) does not contain 0 , indicating that the intermediary is a partial intermediary, consistent with the above analysis. The results of the two mediation effects test indicate the robustness of the mediating effect.

Table 7 Data Results of the Bootstrap Mediation Test for the SPSS Application PROCESS Plugin (Hayes 2013)

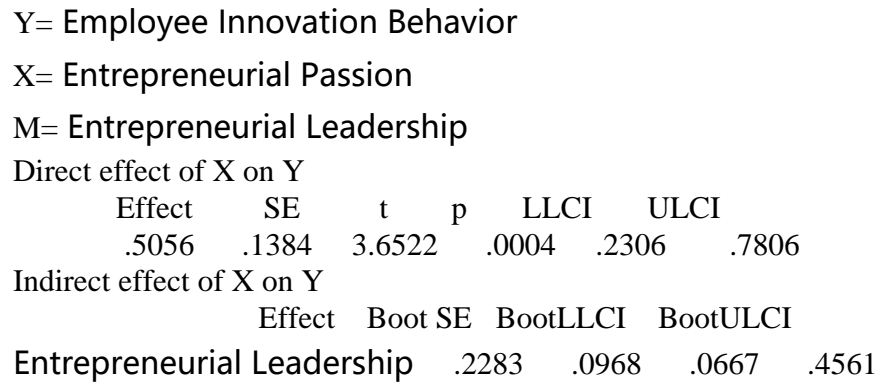

\section{Conclusions and prospects}

\subsection{Research conclusions and significance}

This study analyzes the landing and transformation mechanism of entrepreneurial passion from both theoretical and empirical aspects, and draws the following conclusions:

(1) Entrepreneurial passion will positively influence employee innovation behavior. The main effect of entrepreneurial passion and employee innovation behavior is verified in the regression analysis, which also confirms our conjecture about the passion of entrepreneurship, that is, the entrepreneurial passion of entrepreneurs will give the employees a positive emotional experience. In general, positive emotions at work help to motivate employees' creativity and persistence, and are more likely to make innovative behaviors, consistent with Cardon's (2008) study.

(2) Entrepreneurial passion will positively influence entrepreneurial leadership. According to the hypothesis 2 of this study, entrepreneurs with entrepreneurial enthusiasm are more inclined to adopt entrepreneurial leadership behavior, which implies positive emotions and willingness to take risks.

(3) Entrepreneurial leadership plays a mediating role between entrepreneurial passion and employee innovation behavior. There has been literature showing that entrepreneurial leadership has a certain role in promoting employee innovation behavior, and our regression analysis supports this argument. Based on the above analysis, this study uses the traditional stepwise regression method and the Bootstrap method to test the mediating effect of entrepreneurial leadership respectively. The results show that the mediation effect is robust.

The theoretical contributions of this paper are as follows:

This research starts from the research object of new ventures and empirically tests the intermediary role of entrepreneurial leaders in entrepreneurial passion and employee innovation behavior. Opened the black box of the process of entrepreneurial passion of new entrepreneurs passed 
to employees. Secondly, it has expanded the research on leadership in the context of entrepreneurship and deepened the research on leadership effectiveness in the entrepreneurial environment. Finally, the research conclusion is also an in-depth development of entrepreneurial passion research, and believes that employees are an object of entrepreneurial enterprise that cannot be ignored. Drawing on the theory of emotional infection and related leadership theory, this paper studies the influence of entrepreneurial passion on employees, transcends the static research of individual subjects, and uses dynamic perspectives to study, providing a theoretical reference for the dynamic interaction research between entrepreneurs and employees.

The management implications of this article are as follows:

New entrepreneurs should fully understand the entrepreneurial passion, further understand the importance of entrepreneurial passion, and make reasonable presentations within the organization. Specifically, entrepreneurs should first deeply understand the connotation of entrepreneurial passion and actively use emotional management methods to reasonably demonstrate entrepreneurial passion and convey positive psychological emotions and confidence to employees. Secondly, the government and local incubation platforms should also focus on the intervention and cultivation of the psychological capital of new entrepreneurs, and organize more training on entrepreneurial sentiment and entrepreneurial cognition to help them further interpret the thinking and cognition behind entrepreneurial passion.

\subsection{Research limitations and future prospects}

The limitations of this study are mainly reflected in: First of all, the main variables of this study use the method of the subjective evaluation. Such as the five-point system, there is a certain one-sidedness and subjectivity. Therefore, future research can take experimental methods to improve the objectivity of measurement.

Secondly, in terms of sample collection, the number of qualified research samples was only 106, and the sample distribution of this study was concentrated in Nanjing and Shanghai. Future research should expand the sample coverage and sample size to enhance the universality of the research.

Finally, the research results show that entrepreneurial leadership plays a part in mediating the entrepreneurial passion and employee innovation behavior, which means that there are other path mechanisms for the entrepreneur's entrepreneurial passion to pass to the employee. Future research can explore other factors that drive entrepreneurial entrepreneurship.

\section{References}

[1] Foo M D. Emotions and Entrepreneurial Opportunity Evaluation [J]. Entrepreneurship Theory \& Practice, 2011, 35(2):375-393.

[2] Cardon M S. Is passion contagious? The transference of entrepreneurial passion to employees [J]. Human Resource Management Review, 2008, 18(2):77-86.

[3] Chen X, Liu D, He W. Does passion fuel entrepreneurship and job creativity? A review and preview of passion research [J]. The Oxford handbook of creativity, innovation and entrepreneurship. 2015:159-175.

[4] Cardon M S, Wincent J, Singh J, et al. The Nature and Experience of Entrepreneurial Passion [J]. Academy of Management Review, 2009,34(3):511-532.

[5] Chen X, Yao X, Kotha S. Entrepreneur Passion and Preparedness in Business Plan Presentations: A Persuasion Analysis of Venture Capitalists' Funding Decisions.[J].Academy of Management Journal, 2009,52(1):199-214.

[6] Leitch C M, Volery T. Entrepreneurial leadership: Insights and directions [J]. International Small Business Journal, 2017, 35(2):147-156.

[7] Renko M, Tarabishy A E, Carsrud A L, et al. Understanding and Measuring Entrepreneurial Leadership Style[J]. Journal of Small Business Management, 2015, 53(1):54-74.

[8] Min Y K, Park S M, Miao Q. Entrepreneurial Leadership and Organizational Innovation: Improving Attitudes and Behaviors of Chinese Public Employees [M]. Springer Singapore, 2017. 
[9] Yang Jing. A Review of Entrepreneurial Leadership Research [J]. China Human Resources Development, 2012(8):5-9.

[10] Gupta V, Macmillan I C, Surie G. Entrepreneurial leadership: developing and measuring a cross-cultural construct [J]. Journal of Business Venturing, 2004, 19(2):241-260.

[11] Kleysen R F, Street C T. Toward a multi-dimensional measure of individual innovative behavior [J]. Journal of Intellectual Capital, 2001,2(3):284-296.

[12] Baron $R$ A. The Role of Affect in the Entrepreneurial Process [J]. Academy of Management Review, 2008,33(2):328-340.

[13] Cardon M S, Sudek R, Mitteness C. The impact of perceived entrepreneurial passion on angel investing [J].Frontiers of Entrepreneurship Research, 2009, 29.

[14] Amabile T. A model of creativity and innovation in organisations[J]. Research in organizational behavior, 1988, 10(1):123-167.

[15] Chen M H. Entrepreneurial Leadership and New Ventures: Creativity in Entrepreneurial Teams [J]. Creativity \& Innovation Management, 2007, 16(3):239-249.

[16] Zhou J. The Oxford handbook of creativity, innovation, and entrepreneurship [M]. Oxford University Press, 2015.

[17] Yang Jing, Wang Chongming. Female entrepreneurial leadership: multi-dimensional structure and multi-level influence [J]. Management world, 2013(9):102-117.

[18] Chen Wenpei. Comparison of Multiple Mediating Effects of Entrepreneurial Leaders Affecting Employees' Innovative Behaviors [J].Technical Economy, 2015(10):29-33.

[19] Cardon M S, Gregoire D A, Stevens C E, et al. Measuring entrepreneurial passion: Conceptual foundations and scale validation $\vec{\sim}[\mathrm{J}]$. Journal of Business Venturing, 2013, 28(3):373-396.

[20] Breugst N, Domurath A, Patzelt H, et al. Perceptions of Entrepreneurial Passion and Employees' Commitment to Entrepreneurial Ventures[J]. Entrepreneurship Theory \& Practice, 2012, 36(1):171-192.

[21] Scott S G B R A. Determinants of Innovative Behavior: A Path Model of Individual Innovation in the Workplace [J].Academy of Management Journal, 1994,3(37):580-607.

[22] Xu Juan. Research on the Relationship between Entrepreneurial Leadership Behavior and Entrepreneurial Performance [J]. Jinan University, 2013.

[23] Guo Qingke, Han Dan, Wang Zhao, et al. Effect of positive and negative statements in the personality test [J]. Journal of Psychology, 2006, 38(4):626-632.

[24] Chen Rui, Zheng Yuhuang, Liu Wenjing. Analysis of Mediating Effect: Principle, Program, Bootstrap Method and Its Application [J]. Journal of Marketing Science, 2013(4):120-135. 